\title{
Assessment of Insulin Resistance in Newborn Beagles with the Euglycemic Hyperinsulinemic Clamp ${ }^{1}$
}

\author{
S. E. HULMAN AND R. M. KLIEGMAN \\ The Department of Pediatrics, Case Western Reserve University, Rainbow Babies and Children's Hospital, \\ Cleveland, $\mathrm{OH} 44106$
}

\begin{abstract}
The developmental response to the euglycemic hyperinsulinemic clamp was assessed among newborn and adult beagles to investigate neonatal insulin resistance. Both neonatal dogs and adults were clamped at euglycemic blood glucose concentrations while receiving insulin at a rate of $3.75,15,30,60,75$ or $100 \mathrm{mU} / \mathrm{kg} / \mathrm{min}$ to generate a dose-response curve. Blood glucose levels, plasma insulin concentrations and glucose turnover rates during the basal preclamp fasting period were similar in pups and adult dogs. During the clamp period, blood glucose levels were equivalent to the preclamp period whereas plasma insulin concentrations increased. Total glucose utilization increased from $28.7 \pm 18$ to a plateau level of 114 $\pm 52.3 \mu \mathrm{mol} / \mathrm{kg} / \mathrm{min}$ in adult dogs and from $30.9 \pm 10.9$ to $53.9 \pm 28.9 \mu \mathrm{mol} / \mathrm{kg} / \mathrm{min}$ in newborn dogs. Suppression of endogenous glucose production during euglycemic hyperinsulinemia was close to $100 \%$ among adult dogs, whereas in the newborn pups, endogenous glucose production was suppressed $80 \%$. To determine if the newborn was unable to increase glucose uptake because of a saturation effect on glucose utilization independent of insulin, another group of adult and newborn dogs received a hyperglycemic hyperinsulinemic clamp. In response to the hyperglycemic clamp, adults demonstrated an increase of glucose utilization to $261 \pm 83$, and newborn dogs increased utilization to $227 \pm 76 \mu \mathrm{mol} / \mathrm{kg} / \mathrm{min}$. These results suggest that insulin-mediated glucose utilization in the newborn is attenuated in liver and muscle. Furthermore, these data suggest that a postreceptor defect may be present in newborn dogs when compared with the response among adults. The attenuated response is not due to a reduced capacity to utilize glucose as demonstrated by the hyperglycemic clamp. Substrate- rather than hormone-mediated events may be more important in the newborn mammal for the regulation and utilization of glucose when compared with more mature adults. (Pediatr Res 25:219-223, 1989)
\end{abstract}

Glucose metabolism in the newborn may be imprecisely controlled compared to the adult. In particular, the newborn may have a blunted response to the effects of insulin, either at the receptor or at events distal to the receptor $(1,2)$. This phenomenon is well illustrated in premature newborns with hypergly-

Received April 29, 1988; accepted October 24, 1988.

Correspondence Robert M. Kliegman, M.D., Department of Pediatrics, Rainbow Babies and Children's Hospital, 2101 Adelbert Rd., Cleveland, OH 44106.

Supported by NIH Grant HD20851 and a grant from the Robert J. Frackelton Memorial Fund, University Hospitals, Cleveland $\mathrm{OH}$.

'Presented in part at the 1986 Society for Pediatric Research Meeting, Washington, DC. cemia and glucosuria despite the presence of high circulating plasma insulin concentrations (3). Newborn infants frequently experience hyperglycemia when subjected to an intravenous glucose challenge, in spite of an insulin response by the $\beta$ cells of the pancreas $(1,4,5)$. Insulin resistance occurs, paradoxically, in the face of increased numbers of insulin receptors on fetal and neonatal cells $(6,7)$, increased receptor binding and affinity (7), and lack of down regulation of insulin receptors during the perinatal period among infants exposed to fetal hyperinsulinemia $(8,9)$. The fetus also has an uninterrupted supply of glucose through facilitative transfer across the placenta, and acute regulation of fetal blood glucose concentration is usually not a requirement for the normal mammalian fetus. Postnatally, in the absence of the transplacental glucose supply, exquisite sensitivity to insulin and full function of the overabundance of insulin receptors could potentially produce neonatal hypoglycemia. Teleologically, a period of perinatal insulin resistance could avoid hypoglycemia and maintain glucose availability to less insulin-sensitive tissues such as the brain (10).

The purpose of this study was to investigate two questions: 1) When compared with the adult, is the mammalian newborn insulin-resistant as determined by in vivo methodology? 2) What is the site of this insulin resistance? To investigate these questions, canine newborns were studied with an in vivo technique, the euglycemic hyperinsulinemic clamp, and compared with adult dogs $(11,12)$. In this technique, circulating insulin concentrations are raised to various but constant levels. Hypoglycemia is prevented with a simultaneous infusion of glucose, whose rate then serves as an index of the tissue response of glucose uptake to the insulin stimulus. During hyperinsulinemic euglycemia, the effect of insulin on hepatic glucose output and peripheral tissue (muscle) utilization can be measured and compared between adult and newborn dogs.

\section{MATERIALS AND METHODS}

Animal care. The protocol involved investigation of healthy adult and term newborn beagles, and was approved by the Case Western Reserve University Animal Welfare Committee. Purebred pregnant beagles (Marshall Research Animals Inc, North Rose, NY) with known dates of confinement were housed in kennels and fed a standard diet with free access to water. Cesarean section was performed at term $(60 \pm 2$ days). Newborn pups of both sexes were dried and placed in an Armstrong incubator in which the humidity was maintained at $70 \%$ and temperature at $37^{\circ} \mathrm{C}$. Umbilical arterial and venous catheters (Argyle, St. Louis, MO) were atraumatically placed within $1 \mathrm{~h}$ of delivery $(13,14)$. The pups were weighed, fasted for $3-12 \mathrm{~h}$, and returned to the incubator where they remained undisturbed for the duration of the study. Glucose concentrations remained stable during this study as in previous studies in pups fasted for 3 or $12 \mathrm{~h} \mathrm{(13).} \mathrm{The}$ 
arterial line was used for sample withdrawal, and the venous line, the tip of which was in the inferior vena cava, was used for infusion (13).

The adult animals were purebred 1- to 3-yr-old nonpregnant beagles of both sexes. Each adult was fasted overnight before the study. All adult animals had been trained for venipuncture and harness placement before the actual study to eliminate a stress response. Vascular access was obtained by percutaneous placement of a 22-gauge Angiocath catheter (Deseret Medical Inc., Sandy, Utah) in either the cephalic vein of the foreleg or the medial saphenous vein of the hindleg $30 \mathrm{~min}$ before the study. The animal rested quietly without sedation in a harness with legs dangling for the duration of the study.

Experimental protocol. After umbilical catheter placement, a primed constant infusion with tracer quantities of $\mathrm{D}-\left[6-{ }^{3} \mathrm{H}\right] \mathrm{glu}$ cose was initiated to begin the basal or preclamp period (13). The priming dose was $33.8 \mu \mathrm{Ci} / \mathrm{kg}$ given over $1 \mathrm{~min}$; and the infusion was $0.375 \mu \mathrm{Ci} / \mathrm{kg} / \mathrm{min}$ (sp act $33.1 \mathrm{Ci} / \mathrm{mmol}$ ), delivered by a previously calibrated rotary pump. Blood samples were obtained at 45,60 , and 90 min after the priming dose of D-[6$\left.{ }^{3} \mathrm{H}\right]$ glucose. At the end of the basal preclamp period $(90 \mathrm{~min})$, the euglycemic hyperinsulinemic clamp was begun, and the previously described $\mathrm{D}-\left[6-{ }^{3} \mathrm{H}\right]$ glucose infusion was continued to permit quantitation of glucose metabolized, or $\mathrm{M}$, during the hyperinsulinemic period. The circulating insulin level was raised acutely and maintained at a supraphysiologic level with a primed, constant infusion of insulin. Pups from each litter were randomly studied to receive one rate of insulin infusion, 3.75, 15, 30, 60, 75 , or $100 \mathrm{mU} / \mathrm{kg} / \mathrm{min}$, to generate a dose-response curve. This infusion was preceded by a priming insulin dose equal to $10 \mathrm{~min}$ of the insulin steady-state infusion.

Glucose concentration was determined every 10 min with a Beckman Glucostat (Beckman Instruments, Inc., Fullerton, CA). The glucose value at a particular time interval was inserted into a negative feedback equation that had been programmed into a standard desktop calculator (11). The equation then generated a rate of cold glucose infusion to prevent hypoglycemia or hyperglycemia, and was based on the fluctuation of blood glucose during the clamp from the basal or euglycemic blood glucose value. At 75, 90, and $105 \mathrm{~min}$ after the insulin bolus, additional blood samples were withdrawn for subsequent determination of glucose concentration, insulin, epinephrine, and norepinephrine concentrations, and glucose radioactivity. The adult infusion protocol was identical to the neonatal protocol, except that the primed constant infusion of tracer, D- $\left[6-{ }^{3} \mathrm{H}\right]$ glucose, was 2.64 $\mu \mathrm{Ci} / \mathrm{kg} / \mathrm{min}$. Blood withdrawal timing and sample preparation were identical to that for newborn pups.

To evaluate the saturability of tissue glucose uptake at the maximum insulin effect, additional adult and newborn dogs were given sufficient glucose to raise and maintain blood glucose levels 7-8 $\mathrm{mM}$ above basal values. Insulin was infused at rates that produced the maximum insulin response from the preceding study, and $\mathrm{M}$ was calculated during the hyperglycemic hyperinsulinemic clamp (11). Any increase of glucose uptake above the corresponding euglycemic hyperinsulinemic value for this hyperglycemic clamp is due to glucose-mediated tissue glucose uptake. Because urine glucose loss was negligible, this increment is due to tissue uptake.

The vol of each blood sample was replaced with an equal quantity of heparinized saline. To an aliquot of each sample, an equivalent amount of $10 \%$ perchloric acid was immediately added. The sample was then stored at $-80^{\circ} \mathrm{C}$ for subsequent determination of radioactivity and glucose. An aliquot of plasma was saved to determine insulin and catecholamine concentrations. Catecholamine samples were stored in EGTA as a preservative.

Glucose production (turnover) in the basal preclamp period was determined at each time point using steady-state equations because blood glucose and sp act were constant. The mean of the points in a steady state are reported as the mean of that animal. The steady-state equation for glucose production is: Glucose production equals glucose utilization $=\mathrm{F} / \mathrm{SA}$, where $\mathrm{F}$ $=$ infusion rate in $\mathrm{dpm} / \mathrm{kg} / \mathrm{min}$ and $\mathrm{SA}=$ sp act of the substrate in $\mathrm{dpm} / \mu \mathrm{mol}$. Glucose production is expressed as $\mu \mathrm{mol} / \mathrm{kg} / \mathrm{min}$.

During the glucose infusion of the clamp, the analogous kinetic parameter is $\mathbf{M}$, or total amount of glucose metabolized. It is calculated using the above equation for dilution of a continuous tracer infusion. This can be done because the blood glucose level is maintained at the basal period glucose level during the insulin clamp period. $M=$ exogenous glucose infusion rate + endogenous glucose production.

D- $\left[6-{ }^{3} \mathrm{H}\right]$ glucose was purchased from New England Nuclear (Boston, MA); insulin RIA kits were purchased from Amersham (Arlington Heights, IL) and the CAT-A-Kit assay for catecholamines was determined by radioenzymatic assay and was purchased from Upjohn (Kalamazoo, MI). All enzymes were purchased from Sigma Chemical Co. (St. Louis, MO). Scintiverse was purchased from Fisher Scientific Co., Pittsburgh, PA); exchange resin (AG 50W-X8) was purchased from Bio-Rad Laboratories (Cambridge, MA)

Perchloric acid-precipitated blood was neutralized with $\mathrm{K}_{2} \mathrm{CO}_{3}$, and glucose was then assayed fluorometrically, as described previously (13). Insulin concentration was assayed with a commercial RIA kit, with samples counted for 10 min on a $\gamma$ counter, with appropriate standards and blanks. Epinephrine and norepinephrine were measured with a radioenzyme assay.

Neutralized samples of PCA-precipitated blood were evaporated to dryness to remove ${ }^{3} \mathrm{H}_{2} \mathrm{O}$ and redissolved in distilled deionized water. Labeled glucose was separated from other labeled products by elution from a microcolumn (AG 50W-X8) with pH8 deionized water (13). Radioactivity was counted by liquid scintillation in Scintiverse for 10 min, using a Beckman LS 7500 counter with appropriate internal standards and blanks.

Tabular and text notations will be described as mean 'SD. Data from neonatal and adult dogs were compared statistically with Student's $t$ test, using a standard computer program for calculation. The relationships between substrate levels and kinetic parameters from these animals has been reported elsewhere (15).

\section{RESULTS}

The mean glucose concentration of 25 adult control and 28 newborn dogs during the basal period was $4.17 \pm 1.09$ versus $3.75 \pm 1.18 \mathrm{mM}$ and during euglycemic hyperinsulinemia 4.15 \pm 1.36 versus $3.92 \pm 1.35 \mathrm{mM}$. Mean basal fasting blood glucose concentrations were not different in adult and newborn animals, and basal glucose concentrations were not different than those during the euglycemic hyperinsulinemic clamp period. Mean basal insulin concentrations in adult and newborn dogs were not

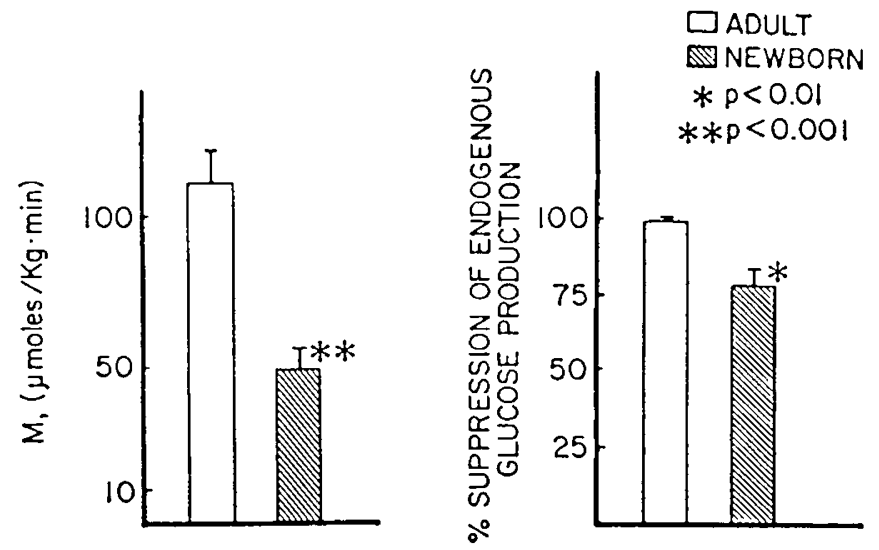

Fig. 1. Glucose metabolized (M) and percentage suppression of endogenous glucose production during the euglycemic hyperinsulinemic clamp. Results are mean $\pm \mathrm{SE}$. 
significantly different $(12.25 \pm 11.4$ versus $16.8 \pm 13.6 \mu \mathrm{U} / \mathrm{cc})$. During the clamp period, mean insulin concentration was significantly elevated in both groups when compared with the basal period. Plasma insulin levels during the clamp period were also similar in both dog groups $(3100 \pm 600$ versus $3870 \pm 670 \mu \mathrm{U} /$ $\mathrm{ml})$.

Figure 1 displays the averaged glucose kinetic parameters measured during euglycemic hyperinsulinemia. These include $\mathrm{M}$, the quantity of glucose metabolized by the whole animal (12), and percentage suppression of endogenous glucose production. Although mean glucose concentrations and mean insulin concentrations during the clamp were similar in adult and newborn dogs, $\mathrm{M}$ was stimulated to a greater extent in the adult animals (adult mean $114.8 \pm 52.3$ versus newborn mean $53.9 \pm$ $28.9 \mu \mathrm{mol} / \mathrm{kg} / \mathrm{min})$. Basal glucose turnover was similar in both groups $(28.7 \pm 18.4$ versus $30.9 \pm 10.9 \mu \mathrm{mol} / \mathrm{kg} / \mathrm{min})$. In addition, the adult dogs demonstrated nearly $100 \%$ suppression of endogenous glucose production in the presence of euglycemic hyperinsulinemia, whereas suppression in the newborn period was less complete $(80.4 \pm 32.3 \%)$, despite similar plasma insulin concentrations (Fig. 1).

A dose-response curve of insulin-stimulated tissue glucose uptake $(\mathrm{M})$ versus insulin concentration for both adult and newborn dogs is shown in Figure 2. Adults demonstrated a more

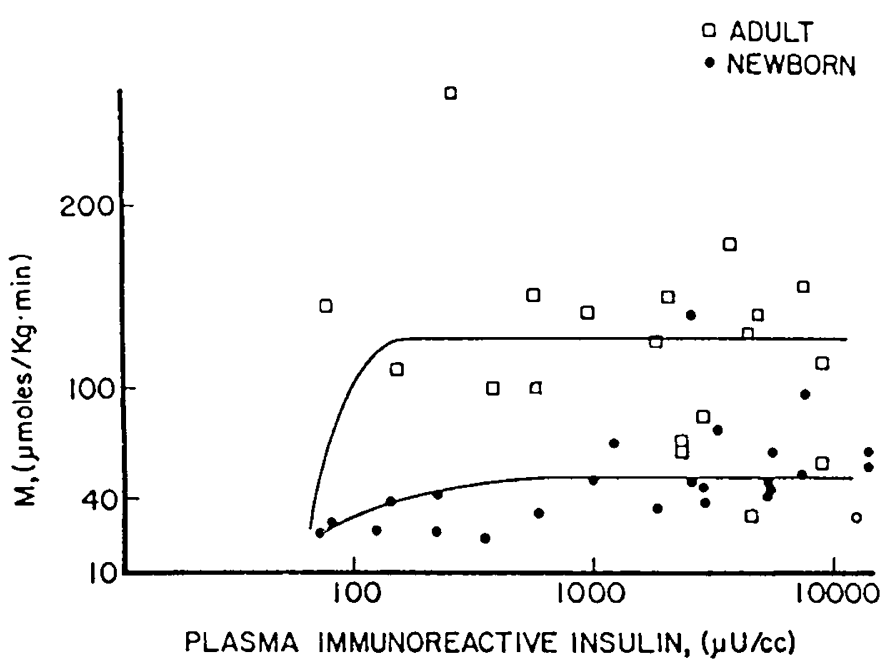

Fig. 2. Dose response curve for insulin-stimulated glucose metabolism in dogs plotted as a function of the achieved plasma immunoreactive insulin concentration during euglycemic hyperinsulinemia. Adult curve $=\mathrm{y}=-17.327 .7 \operatorname{In}_{\mathrm{x}} r=0.1 ;$ newborn curve $=\mathrm{y}=-13.28 .93 \operatorname{In}_{\mathrm{x}} \mathrm{r}=$ 0.57 .

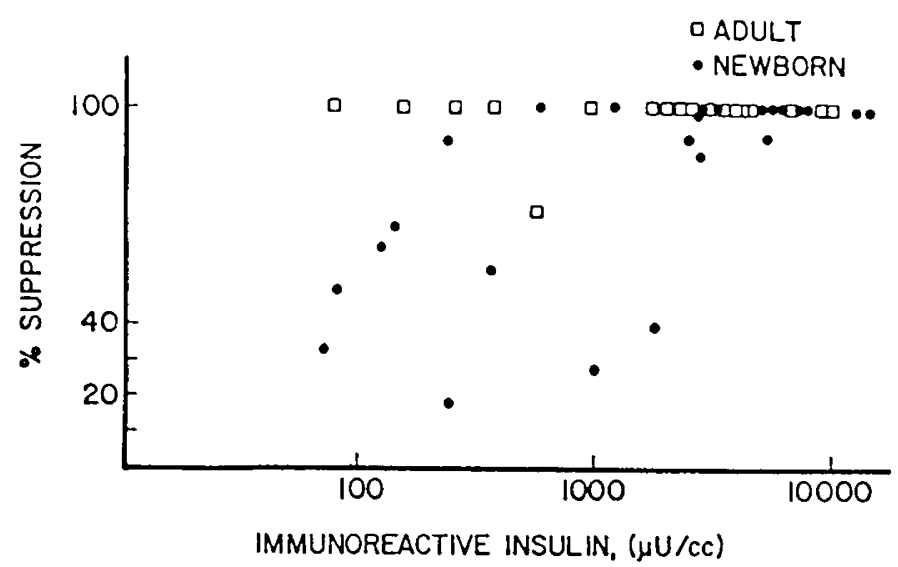

Fig. 3. Suppression of endogenous glucose production as a function of plasma insulin concentration during euglycemic hyperinsulinemia in adult and newborn dogs. rapid response and a higher plateau or maximum response than newborn dogs. In response to equivalent plasma insulin concentrations, maximal glucose utilization increased 4-fold above the basal state in adult dogs versus newborn pups.

To determine if the maximum effects of insulin-mediated glucose utilization in the adult and newborn dog were due to saturation of the tissue's glucose uptake mechanism, we studied five adult and five newborn pups with the hyperglycemic hyperinsulinemic clamp. All subjects for the hyperglycemic hyperinsulinemic clamp were infused with insulin at a rate of $30 \mathrm{mU} /$ $\mathrm{kg} / \mathrm{min}$, which resulted in average plasma insulin levels of 2100 \pm 1300 and $2500 \pm 900 \mu \mathrm{U} / \mathrm{ml}$ in adult and newborn pups. These levels fall on the plateau of the response curves for the adult and newborn dogs and were similar to the insulin levels achieved with this insulin infusion rate for the euglycemic hyperinsulinemic dogs (Fig. 2). During the hyperglycemic phase, plasma glucose levels were increased to values 7-8 $\mathrm{mM}$ above the basal levels (12). In response to hyperglycemic hyperinsulinemia, glucose utilization increased from $114.8 \pm 52.3$ during euglycemic hyperinsulinemia to $261 \pm 83.8 \mu \mathrm{mol} / \mathrm{kg} / \mathrm{min}(p<$ 0.01 ) in adult dogs and from $53.9 \pm 28.9$ to $227.5 \pm 76.4 \mu \mathrm{mol} /$ $\mathrm{kg} / \mathrm{min}(p<0.001)$.

When suppression of endogenous glucose production was examined as a function of insulin concentration, a striking difference between adult and newborn was noted (Fig. 3). A nearly complete suppression of endogenous glucose production in the adult was observed at all insulin concentrations above $80 \mu \mathrm{U} /$ $\mathrm{ml}$. Suppression in newborn dogs was observed only at insulin levels of $700-3000 \mu \mathrm{U} / \mathrm{ml}$. In contrast to the variable degrees of suppression of endogenous glucose production in newborn pups during euglycemic hyperinsulinemia, all newborn dogs demonstrated complete suppression of endogenous glucose production during the hyperglycemic hyperinsulinemic clamp.

Figure 4 relates the two insulin-stimulated parameters to each other; percentage of suppression of endogenous glucose production versus $\mathrm{M}$, or glucose metabolized. In adult animal endogenous glucose production was almost totally suppressed at all levels of $M$. In the newborns, endogenous glucose production was totally suppressed at $\mathrm{M}$ levels of $50 \mu \mathrm{mol} / \mathrm{kg} / \mathrm{min}$ and above.

Because differences in plasma catecholamines may induce insulin resistance, plasma epinephrine and norepinephrine levels were determined during the clamp. Plasma epinephrine levels were similar during the clamp in newborn and adult dogs ( 276 \pm 83 versus $180 \pm 21 \mathrm{pg} / \mathrm{ml}$ ). Plasma norepinephrine levels were elevated in newborn dogs $(626 \pm 113$ versus $282 \pm 54 \mathrm{pg} / \mathrm{ml} p$ $<0.02$ ), compared with adult dogs during the euglycemic hyperinsulinemic clamp.

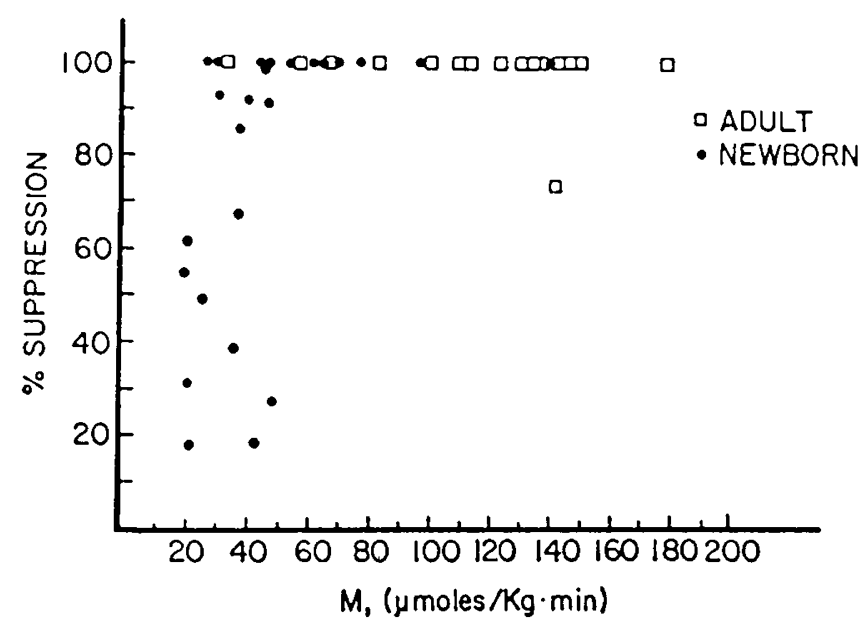

Fig. 4. Suppression of endogenous glucose production as a function of glucose metabolized $(\mathrm{M})$ during the euglycemic hyperinsulinemic clamp in adults and newborn dogs. 


\section{DISCUSSION}

The present results demonstrate that the canine newborn is relatively insulin resistant across a wide range of plasma insulin levels, when compared with the adult. Kolterman et al. (12) have proposed that insulin resistance may be the result of three possible mechanisms: 1 ) an abnormal $\beta$-cell secretory product; 2) circulating insulin antagonists such as counterregulatory hormones, antiinsulin or antiinsulin receptor antibodies; and 3) target-tissue defects (i.e. insulin receptor or postreceptor defects). Watts and Gain (16) have reported an unusual 11,000 D form of insulin in the rat fetus. The occurrence of an atypical insulin molecular form, however, has not been observed in other mammalian species. High-performance liquid chromatography analysis of newborn and adult canine pancreatic insulin extracts had failed to detect different molecular forms of insulin in newborn or adult dogs (Kliegman $\mathrm{R}$, unpublished results).

The transient surge of counterregulatory hormones (epinephrine, norepinephrine) at the time of delivery after umbilical cord severance is well documented (17). Epinephrine may be a counterregulatory hormone and oppose the action of insulin on peripheral tissues. In the adult dog and adult humans, epinephrine inhibits peripheral tissue glucose uptake $(18,19)$. In contrast, norepinephrine has not been found to inhibit tissue glucose uptake $(18,19)$. The comparable plasma epinephrine levels in the newborn and adult dogs suggests that the effects of epinephrine on insulin-mediated glucose uptake are not the cause of the newborn pups' insulin resistance.

Kolterman et al. (12) further characterized target-tissue defects as 1 ) reduced sensitivity to insulin, 2) reduced responsiveness to insulin, or 3) combined defects. Reduced sensitivity to insulin is due to a defect at the level of the receptor itself; either decreased receptor numbers, or reduced receptor affinity. In this type of resistance, high concentrations of insulin overcome the defect and envoke maximum insulin stimulation of tissue, albeit with higher insulin concentrations. Reduced responsiveness to insulin is not achieved by high insulin concentrations. This type of defect may be distal to the insulin-receptor complex and most likely involves reduced responses of intracellular mechanisms (20). In the present study, the maximum insulin-stimulated glucose uptake for the newborn pup does not approach the maximum $\mathrm{M}$ for the adult dog. This is consistent with a postreceptor defect. Nonetheless, a combined defect cannot be ruled out as evident by an apparent shift of the dose response curve to the right at lower insulin concentrations $(100 \mu \mathrm{U} / \mathrm{ml})$ for newborn dogs.

The relatively reduced maximum glucose uptake in newborn dogs may be due to two independent variables: reduced tissue capacity to metabolize glucose or insulin resistance. A reduced capacity to increase tissue glucose uptake was not present in the newborn dog, as evident by the increase of $M$ during the hyperglycemic hyperinsulinemic clamp. This method achieved equivalent plasma insulin levels as the euglycemic clamp, and therefore any increase of tissue glucose uptake is due to glucose-induced augmentation of tissue glucose utilization. Newborn tissue eventually demonstrated equivalent rates of tissue glucose utilization as adults during the combined stimuli of hyperglycemia and hyperinsulinemia. This suggests that glucose-mediated events may be important in the regulation of neonatal glucose metabolism. The observation of enhanced neonatal glucose uptake in the presence of hyperglycemic hyperinsulinemia also suggests that the attenuated glucose uptake during euglycemic hyperinsulinemia is due in part to insulin resistance and not to a reduced tissue capacity to utilize glucose.

Hepatic glucose production in adults is nearly completely suppressed at all levels of insulin, whereas suppression in neonates is less consistent, even at high insulin levels. Adults manifested near total insulin-mediated suppression of endogenous glucose, regardless of the amount of glucose metabolized (M). In contrast, at lower values of $\mathrm{M}$ in the newborn, suppression of endogenous glucose production was incomplete. In most newborn dogs, there appeared to be a relative dissociation between insulin stimulation of the suppression of endogenous glucose production and insulin stimulation of peripheral tissue glucose uptake.

There are many possibilities for the location of the defect responsible for insulin resistance. The stimulation of $\gamma$-aminoisobutyrate transport in muscle by insulin has been shown to be diminished in younger animals when compared with adults $(21$, 22). Cowett et al. (23) demonstrated that the stimulation of glycogen synthesis from labeled precursor was much less pronounced in the newborn rat diaphragm than in older rats. In the same preparation, decreased uptake of deoxyglucose in the newborn indicated decreased effect of insulin on hexose transport. More recent in vitro studies of fetal rat hepatocytes demonstrated that insulin did stimulate the cellular uptake of $\gamma$-aminoisobutyrate and acetate incorporation into lipid (24). Nonetheless, earlier studies had demonstrated that insulin failed to stimulate incorporation of glucose into glycogen in fetal rat hepatocytes, whereas a hyperglycemic medium did (6). The absence of insulinstimulated glycogen synthesis correlated with a lack of conversion of the inactive form of glycogen synthase to the active form. The authors speculated that insulin may be more important for amino acid metabolism than for glycogen synthesis in the immature mammal. Substrate rather than insulin may mediate glucose disposal, as evident in hyperglycemic fetal hepatocytes and by the augmented response of newborn dogs to the hyperglycemic clamp when compared with the euglycemic hyperinsulinemic clamps.

Insulin is known to suppress glycogenolysis and gluconeogenesis; however, some of the pups in this study continued to produce endogenous glucose in spite of very high circulating levels of insulin. This could be due to a postreceptor defect with persistence of enzymatic activity poised toward glycogenolysis and gluconeogenesis. Newborn beagles did not demonstrate hepatic or muscle glycogen synthesis in the presence of euglycemic hyperinsulinemia (25). Furthermore, hepatic glycogen synthesis and activation of glycogen synthase were not observed among adult rats subjected to the euglycemic hyperinsulinemic clamp (20). Hepatic glycogen synthesis after glucose administration proceeds through an indirect pathway by continued incorporation of gluconeogenic precursors into glycogen. This paradoxical incorporation of three carbon precursors demonstrates that gluconeogenesis continued despite hyperglycemia or hyperinsulinemia $(26,27)$. Newborn beagles demonstrate incorporation of lactate into glucose within $3 \mathrm{~h}$ after birth (14). Furthermore, in the presence of hyperglycemia and increased plasma insulin levels, newborn rat pups preferentially incorporate glucose with a recyclable label compared with a nonrecyclable label into hepatic glycogen (27). It is possible that continued endogenous glucose production despite hyperinsulinemia is due to persistent gluconeogenic pathway activity.

Differences in insulin-sensitive body composition between newborn and adult dogs also may play a role in the reduced net insulin-induced $\mathrm{M}$ in neonates. Reduced muscle mass is noted in newborn species, and may result in diminished in vivo responses to insulin. Nonetheless, in vitro studies have demonstrated insulin resistance in newborn relative to adult muscle (24-26). Furthermore, suppression of hepatic glucose production should not be affected by differences in body mass. The effect of hyperinsulinemia and/or hyperglycemia on brain glucose uptake is also controversial. Nonetheless, in the newborn dog, the brain represents only $2.3 \%$ of body wt and accounts for only $36 \%$ of fasting endogenous glucose production (28).

\section{REFERENCES}

1. Lilien LD, Rosenfeld RL, Baccaro MM, Pildes RM 1979 Hyperglycemia in stressed small premature neonates. J Pediatr 94:454-459

2. Pollak A, Cowett R, Schwartz R, Oh W 1978 Glucose disposal in low-birthweight infants during steady-state hyperglycemia: effects of exogenous insulin 
administration. Pediatrics 61:546-549

3. Goldman S, Hirata T 1980 Attenuated response to insulin in very low birthweight infants. Pediatr Res 14:50-53

4. Cowett R, Oh W, Pollak A, Schwartz R, Stonestreet B 1979 Glucose disposal of very low birth weight infants: steady state hyperglycemia produced by constant intravenous glucose infusion. Pediatrics 63:389-396

5. Dweck HS, Cassady G 1974 Glucose intolerance in infants of very low birthweight: I: incidence of hyperglycemia in infants of birth weights 1,100 grams or less. Pediatrics 53:189-195

6. Sinha M, Miller J, Sperling M, Suchy F, Gangner S 1984 Possible dissociation between insulin binding and insulin action in isolated fetal rat hepatocytes. Diabetes 33:864-871

7. Thorsson A, Hintz R 1977 Insulin receptors in the newborn: increase in receptor affinity and number. N Engl J Med 297:908-912

8. Neufeld ND, Kaplan SA, Lippe BM 1981 Monocyte insulin receptors in infants of strictly controlled diabetic mothers. J Clin Endocrinol Metab 52:473-476

9. Neufeld ND, Corbo L 1982 Increased fetal insulin receptors and changes in membrane fluidity and lipid composition. Am J Physiol 243:E246-E250

10. Varma S, Nickerson H, Cowan J, Heteny S 1973 Homeostatic responses to glucose loading in newborn and young dogs. Metabolism 22:1367-1375

11. DeFronzo R, Tobin J, Andres R 1979 Glucose clamp technique: a method for quantifying insulin secretion and resistance. Am J Physiol 230:E214-E223

12. Kolterman O, Insel J, Saekow M, Olefsky J 1980 Mechanisms of insulin resistance in human obesity: evidence for receptor and post-receptor defects. J Clin Invest 65:1272-1284

13. Kliegman R, Miettinen EL, Adam PAJ 1981 Fetal and neonatal responses to maternal canine starvation: circulating fuels and neonatal glucose production. Pediatr Res 15:945-951

14. Kliegman R, Miettinen EL, Adam P 1980 Substrate-turnover interrelationships in fasting neonatal dogs. Am J Physiol 239:E287-E293

15. Hulman S, Kliegman R, Heng J, Crouser E 1988 Relationship of substrate level to turnover rate and hormone concentration: glucose, glucose kinetics and insulin in fasted adult and newborn dogs. Am J Physiol 254:E137-E143
16. Watts C, Gain KR 1984 Insulin in the rat fetus: a new form of circulating insulin. Diabetes 33:50-56

17. Padbury J Diakomanolis E, Hobel C Perelman A, Fisher D 1981 Neonatal adaptation: sympathoadrenal response to umbilical cord cutting. Pediatr Res 15:1483-1487

18. Issekutz B, Allen M 1972 Effect of catecholamines and methylprednisolone on carbohydrate metabolism of dogs. Metabolism 21:48-58

19. Sacca L, Morrone G, Cicala M, Corso G, Ungaro B 1980 Influence of epinephrine, norepinephrine, and isoproterenol on glucose homeostasis in normal man. J Clin Endocrinol Metabol 50:680-684

20. Terrattaz J, Assimacopoulos J, Jeanrenaud B 1986 Inhibition of hepatic glucose production by insulin in vivo in rats: contribution of glycolysis. Am J Physiol 250:E346-351

21. Elsas L, McDonnell R, Rosenberg L 1971 Influence of age on insulin stimulation of amino acid uptake in rat diaphragm. $\mathrm{J}$ Biol Chem 246:6452-6459

22. Riggs T, Wise $\mathrm{H}$, Motz K 1978 Amino acid transport in diaphragms from newborn rats: evidence for insulin resistance. Am J Physiol 235:E304-E310

23. Cowett R, Czech M, Susa J, Schwartz R, Oh W 1980 Blunted muscle responsiveness to insulin in the neonatal rat. Metabolism 29:563-567

24. Miller J, Sinha M, Sperling M, Ganguli S 1986 Insulin stimulates amino acid and lipid metabolism in isolate fetal rat hepatocytes. Pediatr Res 20:609612

25. Hulman S, Kliegman R, Heng J, Crouser E, Huang M 1986 Assessment of insulin resistance in newborn beagles with the euglycemic hyperinsulinemic clamp. Pediatr Res 20(suppl):189 (abstr)

26. Newgard C, Moore S, Foster D, McGarry J 1984 Efficient hepatic glycogen synthesis in refeeding rats requires continued carbon flow through the gluconeogenic pathway. J Biol Chem 259:6958-6963

27. Kunst C, Kliegman R, Trindade C 1987 The glycogen synthesis glucose "paradox" in neonatal murine hepatic glycogen synthesis. Pediatr Res 21(suppl):343 (abstr)

28. Huang M, Kliegman R, Trindade C, Kall D, Voelker K 1988 Allocation of systemic glucose output to cerebral utilization as a function of fetal canine growth. Am J Physiol 254:E579-587 